\title{
TRANSFORMANDO MENORES ORPHÃOS OU ABANDONADOS EM FEITORES DO CAMPO, POMICULTORES, HORTICULTORES, JARDINOCULTORES, ABEGÕES E PROFISSIONAIS PRÁTICOS NOS DIVERSOS OFFÍCIOS AGRÍCOLAS: A CRIAÇÃO DO PATRONATO AGRÍCOLA NO PARÁ REPUBLICANO
}

\author{
Gleice Izaura da Costa Oliveira \\ (IFPA) \\ gleiceoliveira@hotmail.com \\ Genylton Odilon Rêgo da Rocha \\ genylton@ufpa.br
}

\begin{abstract}
RESUMO
Versa-se neste artigo sobre a criação, no Estado do Pará, do Patronato Agrícola Manoel Barata, fundado no período denominado de República Velha e/ou Primeira República (1889-1930). No cenário educacional, a fundação desta instituição não aconteceu gratuitamente, mas foi resultado de uma série de fatores de ordem econômica, político e social que estavam ocorrendo no Brasil e no Pará. Para coleta de dados sobre a criação desta instituição realizou-se pesquisa documental nos arquivos da extinta Escola Agrotécnica Federal do Pará, no Arquivo Público do Estado do Pará e no Setor de Obras Raras da Biblioteca Pública. Dentre os principais documentos analisados destacamos o Decreto Federal No 12.893 , de 28 de fevereiro de 1918, o Decreto Lei $N^{\circ} 1.957$, de 17 de novembro de 1920, o Decreto Federal No 15.149, de $1^{\circ}$ de Dezembro de 192, Mensagem apresentada ao Congresso do Estado do Pará pelo Governador Lauro Nina Sodré em 1893 e Mensagem apresentada ao Congresso Legislativo do Estado do Pará, em sessão solene de abertura da $2^{\mathrm{a}}$ reunião de sua $40^{\circ}$ legislatura a 7 de setembro de 1919 , pelo Governador Lauro Nina Sodré, em seu segundo mandato. Promoveu-se, também, pesquisa bibliográfica que subsidiou a caracterização e os eventos que ocorreram na sociedade brasileira e paraense do período pesquisado. As análises realizadas permite-nos afirmar que a fundação do Patronato Agrícola Manoel Barata, no período Republicano, foi parte de uma política nacional que objetivou retirar do convívio social a "infância e juventude pobre", que com seus hábitos e atitudes incomodava e comprometia o projeto da elite do período.

Palavras-Chave: Ensino Profissional Agrícola; Patronato Agrícola; Primeira República; Pará.
\end{abstract}

\section{TRANSFORMING ORPHANS SMALLEST OR ABANDONED IN MANAGER OF FIELD,ORCHARDISTS, HORTICULTURISTS, GARDENCULTURISTS, MANAGERS AND PROFESSIONAL PRACTICE IN VARIOUS AGRICULTURAL OFFICIO: CREATINGTHE AGRICULTURAL EMPLOYERS FOR REPUBLICANS.}

\begin{abstract}
:
Versa is this article about the creation, in Para, Agricultural Employer's ManuelBarata, founded in the period called the Old Republic and /or First Republic(1889-1930). In the educational setting, the foundation of this institution did not happen for free, but was the result of a number of factors of economic, political and social that were taking place in Brazil and Pará to collect data on the creation of this institutionwas carried out
\end{abstract}


documentary research in the archives of the defunct FederalAgrotechnical School of Pará, in the Public Archives of the State of Pará and Rare Books Division of the Public Library. The main documents reviewed highlight theFederal Decree No. 12893 of February 28, 1918, Decree Law No. 1957 of November 17, 1920, Federal Decree No.15149 of 1 December 192, Messagesubmitted to Congress Para State Governor Lauro Nina Sodré in 1893 and displayed at the Congress legislature of the State of Pará, in the official opening ceremony of the $2^{\text {nd }}$ meeting of its $40^{\text {th }}$ legislature September 7, 1919, by Governor Lauro Nina Sodré, in his second term. Promoted is also literature that supported the characterization and the events that occurred in Brazil, and Para of the researched period. The analysis performed allows us to state that the foundation of the Agricultural Employers' Manuel Barata, during Republican, was part of a national policy aimed at removing from society the "poor childhood and youth,"who with hishabits and attitudes bothered and affected the project of the elite of the period.

Keywords: Agricultural Vocational Education, Agricultural Employers, First Republic, Pará.

\section{1- As ações educacionais para o Ensino Profissional Agrícola durante a Primeira República}

O Patronato Agrícola Manoel Barata foi fundado no Estado do Pará durante o período denominado por alguns Historiadores de República Velha e/ou Primeira República (1889-1930). A implantação do regime Republicano no Brasil foi o resultado de um conjunto de situações que começaram a se configurar ainda durante o Império e estavam relacionadas aos aspectos econômicos, políticos e sociais.

O regime republicano depositou na educação o papel de formar uma nova sociedade alinhada aos princípios liberais de progresso, ordem, civilização e modernidade, refletindo as transformações por que passava o sistema capitalista.

Para educar o contingente populacional que havia nas cidades, foram fundadas algumas instituições nesse período, entre estas destacamos, em função do objeto deste estudo, os Patronatos Agrícolas.

A fundação dos Patronatos Agrícolas, vinculados ao Ministério da Agricultura, Indústria e Comércio significou uma das ações concretas para a educação nesse período:

Os patronatos agrícolas foram investimentos voltados para a formação de trabalhadores a partir de concepções fundadas nos conhecimentos científicos, objetivando uma agricultura racionalizada; foram inscritos; também, enquanto um dos meios de intervir sobre os setores pobres da sociedade, concorrendo para a modernização social e cultural. (OLIVEIRA, 2003, p.24)

Essas instituições funcionavam como instrumentos paliativos para os problemas sociais e urbanos, pois se destinavam à infância desvalida das cidades, atendendo aos interesses dos segmentos aristocráticos empenhados em construir uma imagem moderna da sociedade brasileira, mediante a circulação de um discurso higienizante.

Nesse contexto a educação profissional poderia contribuir para a formação de hábitos e atitudes necessários para a convivência nesta sociedade, por esse motivo, foi 
criada uma comissão para estudar de que forma o ensino profissionalizante poderia ser reestruturado para contribuir com a modernização da sociedade brasileira.

Durante a República, a educação profissional manteve o mesmo objetivo e organização do período Imperial, ou seja, de atender as classes populares, pobres, a infância desvalida e os órfãos (MANFREDI, 2002; NAGLE, 1976), porém, foram realizadas algumas tentativas para mudar a organização dessa modalidade de ensino. Eram necessárias novas diretrizes para a educação profissional, devido às mudanças que ocorreram no setor social e econômico do país.

Nesse período, foi instituída a "Comissão Luderitz" 1, também conhecida como "Serviço de Remodelação do Ensino Profissional Técnico".

O relatório desta comissão foi apresentado ao Ministro da Agricultura, Indústria e Comércio em 1924 e tinha recomendações para que a educação profissional formasse nos indivíduos provenientes das classes menos favorecidas as habilidades necessárias para ser a mão-de-obra apropriada ao desenvolvimento industrial no país.

As recomendações deste relatório serviram de referência para algumas medidas que foram implantadas na educação profissional.

As sugestões da Comissão Luderitz transformaram-se em um projeto denominado "Regulamento do Ensino Profissional Técnico", onde foi previsto um conjunto de modificações para o ensino técnico industrial ministrado nas Escolas de Aprendizes Artífices. Saliente-se, porem, que as sugestões da comissão tiveram grande impacto também sobre o ensino profissional agrícola existente no Brasil.

Sabe-se que desde o período Colonial, a agricultura nacional baseava-se no latifúndio, na monocultura de exportação, no trabalho escravo, na abundância de terras novas e férteis e no descaso pelo manuseio e conservação do solo. Isso fazia com que não houvesse diversificação e quase nenhuma qualificação da força de trabalho. Por isso não era necessário ter uma escola para formação de mão-de-obra para lavoura.

Entretanto, com as mudanças que foram se processando na economia durante os primeiros anos do regime republicano, houve necessidade de formação de mão-de-obra qualificada, pois a substituição do trabalho escravo pelo trabalho assalariado após a abolição do regime escravista e a substituição de uma economia agrário- comercialexportadora pela urbano industrial, exigiam trabalhadores mais preparados no campo.

Como alternativa para a educação profissional agrícola, nesse período foram fundados, em vários estados da Federação, os Patronatos Agrícolas, Aprendizados Agrícolas e as Escolas superiores de Agricultura e Medicina Veterinária. (NAGLE, 1976; MENDONÇA, 2006)

Várias justificativas foram apontadas para a fundação dessas instituições de ensino agrícola, dentre as quais pode-se destacar: a atenção do governo da época para com os problemas localizados no meio rural. No caso específico dos patronatos agrícolas, estes poderiam ajudar no aumento progressivo da capacidade produtora do país, impulsionando o desenvolvimento econômico, pois era necessário cuidar, antes de tudo, da preparação do elemento produtor.

A instrução popular ou a falta de uma sólida organização do ensino foram situações educacionais apontadas como responsáveis pelo atraso intelectual e material de nossa população trabalhadora e constituíram justificativas para a criação dos patronatos agrícolas, pois, segundo Oliveira (2003, p. 27):

[...] criava remoras ao progresso do trabalho fabril e agrícola, impedindo o surto da prosperidade mercantil. .Os seus produtos mais imediatamente constatáveis e de difícil solução, classificado como chagas, era o analfabetismo, a indigência e a vagabundagem. O que era proposto por meio dos patronatos agrícolas era assegurar a cultura moral à infância, 
alvo daquela instituição, acompanhada da faculdade de ler, compreender e raciocinar. A tarefa seria completada ao especializá-las num ofício ou numa arte. (grifos no original)

Assim, a necessidade de formar operários contribuiu para a criação dos patronatos agrícolas, na medida em que era necessário adestrar o elemento nacional, entre este o trabalhador rural.

Os patronatos agrícolas minimizariam também um problema que estava se formando nos centros urbanos: a infância abandonada e aqueles que tinham dificuldade em ser mantidos por seus familiares. Parte da infância que se encontrava pela rua, os órfãos, os que eram tomados pelas forças de segurança e aqueles que seus responsáveis declaravam sem recursos para mantê-los ou por serem de difícil controle seriam encaminhados para estas instituições.

Essa situação é descrita por meio do ofício $\mathrm{N}^{\mathrm{o}} 379$, de 29.11 .1918 , onde o Dr.Dulphe Pinheiro Machado, Diretor Geral do Serviço do Povoamento do Ministério da Agricultura, Indústria e Comércio, envia ao Ministro da Agricultura um relatório na qual explica a situação da infância desvalida no Brasil nos primeiros anos da República. Este documento, transcrito abaixo, confirma o fato de as políticas para a educação profissional agrícola terem servido durante a República como alternativa para disciplinar as classes menos favorecidas aos padrões de modernidade exigidos para uma sociedade que estava começando um processo de industrialização, ou seja, de serem disciplinados como força de trabalho:

Exmo.sr.Ministro da Agricultura, Indústria e Comércio

Prezado Senhor,

"Em relatório publicado em maio de 1917, descreve o $\mathrm{sr}^{\mathrm{0}}$ Ministro da Justiça e Negócios o seguinte: Não é lícito adiar mais a situação do problema da infância desvalida. O menor abandonado é um futuro hóspede das prisões; a sociedade culpada do infortúnio dele, ainda castiga sua victima. Constrangia-se-me o coração ao ver os pequenos na deletéria com profissionais do delito nas salas, da casa de detenção. Horroriza-me a idéia de que partia para a Colônia Correcional, de volta com a escoria da sociedade com os vagabundos e gatunos.

Com a escassa verba obra Preparei em sua dependência na detenção, um aposento arejado e vasto para menores abandonados. O governo reservou para os órfãos pobres os lugares de internos gratuitos no Colégio Pedro II. Fez alguma coisa para os infelizes; porém é pouco".

A previdência esclarecida de Alfredo Pinto, que estabeleceu um depósito para menores na cidade, a Escola Premonitória no Campo, esta não foi concluída. Preme-se uma centena de meninos em escassos dormitórios, instalaram-se oficinas em antigos pardieiros, baixos maus ventilados e em ruínas. O depósito provisório para 50 crianças converteuse em asylos, porque não havia para onde mandá-los. (o grifo é do relator). Fez um arremedo de officinas e para ali a polícia ia enviando os desgraçados. Entretanto a lotação está excedida, não cabe mais ninguém. Por isso os delegados sentem a necessidade de enviar delituosos para a casa de Detenção. Presos porque não tem tetos e perderão os Paes! A sociedade está formando uma legião de revoltados. Presidentes Ministros e Chefes de Polícia silenciaram o quanto possível. A crise apavorava; todos reprimiam os seus sentimentos generosos". "Agora porém, é demais... Como bem observa V.Excia. nas citações que acabamos de fazer; partindo tanto do poder Executivo, como do Legislativo, já partiu o grito de alarme sobre a situação que não pode permanecer na capital do país, no coração da República. Seria pueril, pretender a Direção do 
Serviço de Povoamento oferecer ou propor ao governo, medidas que, de modo Cabal, resolvesse os problemas, cuja transcendênciatem sido evidenciadas, no mundo inteiro por cientistas os mais notáveis. E nem mesmo por questão social tão magna como essa faz parte do Estatuto que regula suas atribuições presentes. Por isso porém, não lhe impede que seja permitido sugerir ao esclarecido espírito de V.Excia, providências que, poderão talvez, attenuar a gravidade dos factos narrados pelo $\mathrm{Sr}$. Ministro da Justiça. Em circunstâncias análogas, tem sido essa norma de proceder este departamento público. Seja esta repartição amparar esses menores, localizá-los em pontos adequados, até que o Congresso, em sua alta sabedoria, delibere, tomar sobre os mesmos, resoluções compatíveis com o grau de adiantamento e progresso em que nos encontramos. Próximo ao Distrito Federal, existe sem utilidades alguma, no momento, dois próprios nacionais que podem convir ao fim collimado: $\underline{o}$ antigo Sanatório de Lavrinha, distando $14 \mathrm{~km}$. de Piquete, no estado de São Paulo, e o Lazaretto da Ilha Grande. Foi o primeiro entregue ao Patrimônio Nacional pelo Ministro da Guerra, existenteali enormes edifícios, hoje em completo desprezo. Resta saber para que já providenciou se os terrenos anexos têm área suficiente e se presta aos trabalhos agrícolas. O segundo está a cargo do Ministro da Justiça, constando que as terras da Ilha Grande são de feracidade indiscutível. Recai a opção num ou noutro desse próprio, mister, que se faça meticuloso exame local, para que se possa aquilatar as vantagens que advirão de semelhante empreendimento. É do programa da Diretoria do Povoamento organizar um outro centro agrícola de menores, ministrandolhes além da precisa instrução, verdadeiras praticultura, de modo que formem pequenos cultivadores e operários, aptos para os diferentes misteres da propriedade rural, explorada de acordo com as mais modernas regras agronômicas.O ensino deverá ser essencialmente practico, pondo-se ao alcance do menor os méthodos racionais de exploração de solo, manejo dos instrumentos agrários, conhecimentos relativos á criação, hygiene e alimentação dos animais, em geral. Nesse Centro Colonial, cuidar-se-á também de sua educação phísica por meio de exercícios gynásticos e militares e jogos apropriados à idade. Organizar-se- à um campo de produção de sementes de plantas úteis, bem como viveiros dessas mesmas plantas, de árvores frutíferas, de essências florestais, principalmente o eucalypitus, para distribuição gratuita aos agricultores registrados neste Ministério. Em favor de cada menor poderse-á estabelecer um pequeno pecúlio, de modo análogo ao que está fazendo o Estado de São Paulo à respeito dos condenados empregados nas construções de estradas de rodagens, pecúlio esse composto de uma parte da importância correspondente às atividades de cada um, para serlhes entregue na ocasião oportuna. Caso entenda V.Excia. haver qualquer parcela de proveito ao interesse público, na proposta que respeitosamente, dirijo julgar acertadas, podendo-se então organizar o projecto de instrução concernentes aos respectivos trabalho.(MACHADO, 1918 citado por SILVA, 2004, p.30-32, grifos no original)

No período que esse documento foi divulgado, o presidente Wenceslau Braz, em 28 de fevereiro de 1918, autorizou o Ministério da Agricultura, Indústria e Comércio a criar os Patronatos Agrícolas, no Brasil:

DECRETO Nº 12.893, DE 28.02.1918 


\title{
O PRESIDENTE DA REPÚBLICA DOS ESTADOS UNIDOS DO BRASIL
}

\begin{abstract}
AUTORIZA AO MINISTÉRIO DA AGRICULTURA, INDÚSTRIA E COMÉRCIO A CRIAR PATRONATO AGRÍCOLA PARA EDUCAÇÃO DE MENORES DESVALIDOS NOS POSTOS ZOOTÉCNICOS, FAZENDAS-MODELO ,NÚCLEOS COLONIAIS E OUTROS ESTABELECIMENTOS DO MINISTÉRIO:
\end{abstract}

- considerando que ao governo cabe, por todos os modos, impulsionaro movimento de transformação econômica do país, pelo aumento progressivo de sua capacidade de produção

- considerando que, entre os meios capazes de fecundação profunda da vida nacional, avulta da implantação do ensino agrícola, com sua caracterização positiva e concreta condizente a resultado imediatamente produtivo;

- considerando que por mais vigorosamente que possam atuar as providências já iniciadas, constituem-nas a apenas fatores concorrentes a não decisiva, pela razão de que em matéria de expansão agrária para conseguir êxito permanente durável, faz-se necessário cuidar antes de tudo da preparação do elemento produtor;

- considerando,que o ensino profissional tentará cada vez mais frutuosa produção agropecuária, ao mesmo passo que concorrerá para se estabelecer o equilíbrio entre a população da cidade e a população dos campos, necessárias pela fascinação que as grandes capitais podem exercer no espírito da mocidade desaparelhada para o exercício de qualquer emprego ou atividade honesta;

- considerando, mais que é dever do Governo; contribuir para aumentar a população rural e formar verdadeiro agricultor, aproveitando treinamento, como fator de riqueza elemento nacional;

- considerando, finalmente, ser ao mesmo tempo, obra de previsão sócioeconômica empregar na formação de grêmio rural, donde há de se profanar o engrandecimento real do futuro do país, os menores abandonados ou sem meios de subsistências por falta de ocupação legítima;

E, usando da autorização no Art.1 ${ }^{\circ}$, da Lei $\mathrm{N}^{\circ} 3.316$ de 16 de Agosto de 1917:

\section{DECRETA}

Art. $1^{\circ}$ - Fica autorizado o ministério do estado dos Negócios da Agricultura, Indústria e Comércio criar em Postos Zootécnicos , Fazendas - modelo de criação, Núcleos Coloniais e outros Estabelecimentos do Ministério Patronato Agrícola destinado a ministrar, além da instrução primária e cívica, noções práticas de Agricultura, Zootecnia e Veterinária a menores desvalidos;

Art. $2^{\circ}$ - Nos Patronatos criados, em virtude do presente Decreto, serão aproveitados os serviços dos funcionários adidos e do pessoal técnico administrativo atualmente existentes naqueles estabelecimentos, de acordo com instruções que lhe forem expedidas pelo Ministério do Estado dos negócios da Agricultura, Indústria e Comércio;

Art. $3^{\circ}$ - Revogam-se as disposições em contrário.

$\mathrm{Aa} /$ Wenceslau Braz P.Gomes

Presidente (SILVA, 2004, p.23-24)

No Decreto $N^{\circ} 13.076$, de 25 de julho de 1919 consta o regulamento que trata da criação desses patronatos em todo o Brasil. Para melhor compreendermos o teor deste 
decreto, inserimos o trecho onde consta a natureza e o objetivo da educação profissional agrícola daquela época, destinada aos pobres, órfãos e desfavorecidos de fortuna:

[...] se destinam às classes pobres, e visam à educação moral, cívica, física e profissional de menores desvalidos, e daqueles que por insuficiência da capacidade de educação na família, forem postos, por quem de direito, à disposição do Ministério da Agricultura, Indústria e Comércio (Art. $1^{\circ}$ ); em seu conjunto, constituem um instituto de assistência, proteção e tutela moral aos menores (...) recorrendo para esse efeito ao trabalho agrícola, sem outro intuito que não o de utilizar sua ação educativa e regeneradora , com o fim de nos dirigir e orientar, até incorporá-los ao meio rural (Art. $2^{\circ}$ ). Os internados devem ser menores, reconhecidamente desvalidos, com a idade de 10 a 16 anos.(Art. 35), que não podem ser delinqüientes, portadores de doença contagiosa ou deficiência orgânica, que os inabilite para os serviços agrícolas ou de indústria rural. (Art. 40): São dois os cursos ministrados:o curso primário[...] e o ensino profissional [...] compreendendo este estudos do solo, instrumentos agrários, escolha de sementes, preparação e aproveitamento das matérias fertilizantes, jardinocultura, insetos úteis e prejudiciais à agricultura, pecuária, higiene, laticínios, apicultura, sericicultura, beneficiamento e embalagem dos produtos da lavoura, contabilidade agrícola etc. $\mathrm{O}$ curso e os trabalhos agrícolas proporcionarão parte da renda da instituição[...]; introduz-se aqui o princípio de "industrialização das escolas", semelhante ao das escolas industriais. (NAGLE, 1976, p.183-184)

O conteúdo das prescrições oficiais que regulamentaram a fundação e organização dos patronatos agrícolas permite identificar qual era a função dos conhecimentos ensinados nestes estabelecimentos de ensino e o papel que estas instituições ocupavam na formação da sociedade urbana industrial.

Os Patronatos Agrícolas, quanto ao aspecto formativo, cumpriam três objetivos: formar o elemento produtor, discipliná-lo e alfabetizá-lo. Estas funções tinham como particularidade assegurar uma formação moral à infância pobre, desvalida, que se aglomerava nos grandes centros urbanos. Para cumprir esses objetivos, eram dadas noções de conhecimentos disciplinares militares. Para cumprir este objetivo, verificava-se a presença da instituição policial, não apenas com a função de arregimentar esses menores e transferi-los para as instituições; esta também contribuía para formar o perfil disciplinador da instituição.

Através de uma instrução elementar, os alunos aprendiam a ler e, paralelo a estes conhecimentos, tinham aulas de artes complementadas com algum ofício relacionado à área agropecuária, de onde saíam habilitados em horticultura, jardinagem, pomicultura, pecuária e cultivo de plantas industriais.

No estado do Pará, foi fundado o Patronato Agrícola Manoel Barata, configurando-se como uma das expressões da política para a educação profissional na época. 


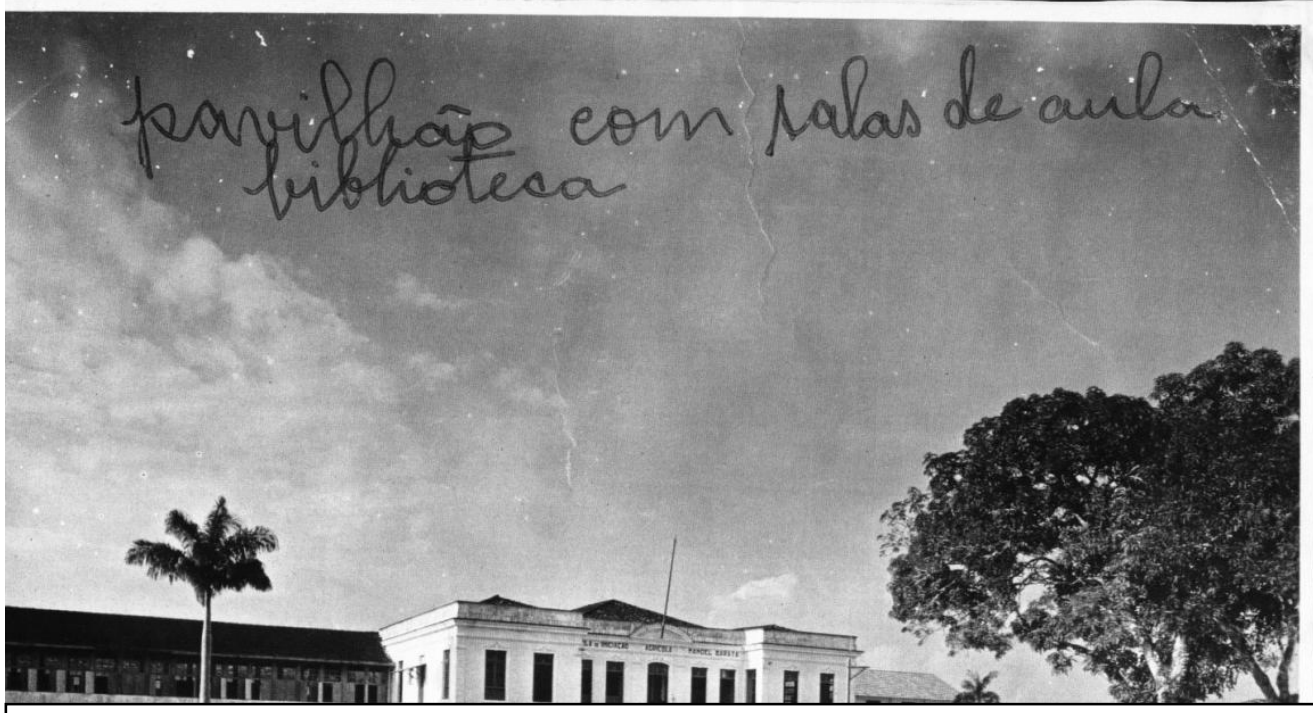

Figura 1: Patronato Agrícola Manoel Barata- Outeiro (Pará)

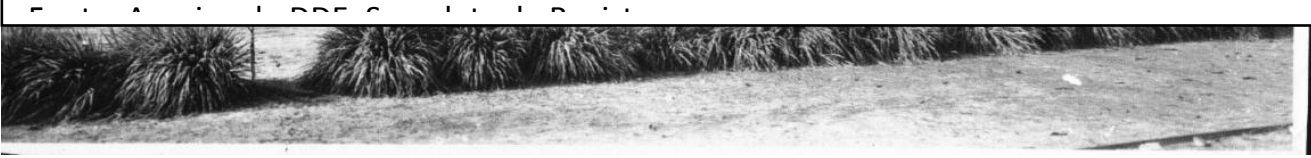

O quadro seguinte relaciona os patronatos agrícolas fundados em várias localidades do Brasil no período denominado Primeira República.

QUADRO 1: Relação dos Patronatos Agrícolas fundados no Brasil

\begin{tabular}{|l|l|l|l|}
\hline Patronato Agrícola & Localização & Decreto Criação & Inauguração \\
\hline 1Visconde de Mauá & Ouro Fino/MG & $12.893,28 / 2 / 1918$ & $3 / 7 / 1918$ \\
\hline 2Monção & $\begin{array}{l}\text { S.Bárbara do Rio } \\
\text { Pardo/SP }\end{array}$ & $12.893,28 / 2 / 18$ & $15 / 7 / 1918$ \\
\hline 3Pereira Lima & Sete Lagoas/MG & $12.893,28 / 2 / 18$ & $26 / 7 / 1918$ \\
\hline 4Delfim Moreira & Silvestre Ferraz/SP & $13.112,20 / 7 / 1918$ & $10 / 8 / 1918$ \\
\hline 5.Wenceslau Braz & Caxambu/MG & $13.070,15 / 6 / 1918$ & $12 / 11 / 1918$ \\
\hline 6S.Pinheiro Machado & Porto Alegre/RS & $13.508 .10 / 3 / 1919$ & $1 / 7 / 1919$ \\
\hline 7Campos Salles & PassaQuatro/MG & $3.6774,7 / 1 / 1919$ & $15 / 11 / 1919$ \\
\hline 8Lindolpho Coimbra & Muzambinho/MG & $14.386,1 / 10 / 1920$ & $1 / 7 / 1921$ \\
\hline 9 Barão de Lucena & Jaboatão/PE & $14.275,28 / 7 / 1920$ & $1 / 7 / 1921$ \\
\hline 10Casa dos Ottoni & Serro/MG & $13.111,20 / 07 / 1918$ & $18 / 10 / 1921$ \\
\hline 11José Bonifácio & Jaboticabal/SP & $15.150,1 / 12 / 1921$ & $1 / 5 / 1922$ \\
\hline 12 Manoel Barata & Outeiro/PA & $\mathbf{1 5 . 1 4 9 , 1 / 1 2 / 1 9 2 1}$ & $\mathbf{7 / 9 / 1 9 2 2}$ \\
\hline 13 Visconde da Graça & Pelotas/RS & $15.102,9 / 11 / 1921$ & $12 / 10 / 1923$ \\
\hline 14 Diogo Feijó & Ribeirão preto/SP & $15.803,11 / 11 / 1922$ & $28 / 11 / 1923$ \\
\hline 15 Vidal de Negreiros & Bananeiras/PE & $14.118,27 / 3 / 1920$ & $7 / 9 / 1924$ \\
\hline 16Annitapolis & SC & $13.118,27 / 3 / 1920$ & $7 / 9 / 1924$ \\
\hline 17Dr.João Coimbra & Tammandaré/PE & $16.105,21 / 7 / 1923$ & $5 / 11 / 1924$ \\
\hline 18 Rio Branco & BA & & $12 / 10 / 1926$ \\
\hline 19 Marquez de Abrantes & BA & & $12 / 10 / 1926$ \\
\hline 20 Arthur Bernardes & Viçosa/MG & & $7 / 11 / 1926$ \\
\hline
\end{tabular}

FONTE: Oliveira (2003, p.37, grifos nossos)

\section{2- O Pará no contexto do período republicano}


Antes de ser proclamada a República, o Pará, juntamente com os Estados do Amazonas e Acre, constituíam os pólos econômicos de produção da borracha (BORGES, 1983). A riqueza proporcionada pela exportação deste produto mudou o perfil econômico, social e urbano desses Estados, contribuindo para uma nova configuração da sociedade.

Borges (1983, p.72-73) descreve os efeitos do auge do período da borracha na sociedade paraense da época:

[...]ótima a situação financeira e em firme progressão dos Estados do Pará e Amazonas privilegiados com seringais nativos e exploração da borracha, cujo opulento comércio internacional criaram e dominaram sem competidor. Exportação iniciada em 1827, com 11 mil toneladas, elevadas no governo Lauro Sodré (1891-1896), de 16 e 20 mil toneladas [...] já então a borracha proporcionara à Amazônia a abertura de seus portos à navegação e comércio das nações, intensa migração nacional e estrangeira, grande frota fluvial a vapor e considerável navegação de cabotagem e internacional [...]a Belém telégrafo submarino e subfluvial, bancos nacionais e estrangeiros, poderosas firmas comerciais, na maioria, estrangeiras, de exportação e importação .

Segundo Leal (2002) a riqueza acumulada graças à exportação da borracha não se limitou apenas a favorecer o bem estar das elites paraenses de então. Esta contribuiu para o aumento populacional da cidade de Belém significativamente, pois com a extinção do trabalho escravo, a exploração dos extensos seringais necessitava de um número elevado de trabalhadores para que esse produto garantisse vultuosos lucros aos seringalistas.

Entre as alternativas de contratação da mão-de-obra, estavam desde os imigrantes europeus até a importação de braços nordestinos ${ }^{2}$, em especial os cearenses.

A partir de 1850, as correntes migratórias, gerando produção e mão -de obra, ultrapassaram as fronteiras do Pará, chegando às regiões dos rios Madeira e Purus.[...] A contribuição externa para a ostentação da atividade extrativa da borracha e agrícola no Pará foi, fundamentalmente, a nordestina.(MONTEIRO, 2005, p.157)

Dessa forma, o nordeste tornou-se o principal fornecedor da "força de trabalho para a economia gomífera" (SARGES, 2002, p.77). Embora houvesse incentivo do Governo do Estado, nem todos se dirigiam aos seringais, ocasionando para a população da cidade de Belém um elevado número de subempregados e desempregados. Isso refletiu na infraestrutura da cidade, pois da forma como Belém estava organizada, mostrou-se insuficiente para abrigar essa população .

A organização social da cidade de Belém dinamizou o aspecto intelectual e o aumento demográfico estabeleceu outras formas de relações sociais, assim como proporcionou a concentração das fortunas entre os novos setores dominantes. Esta classe era formada por comerciantes (na sua maioria portugueses) e profissionais liberais (eram os filhos das famílias ricas que estudaram nas universidades européias).

Devido à exportação da borracha, Belém era uma cidade onde corria muito dinheiro. Adventícios de todas as partes do Brasil, e do mundo, afluíam à capital do EL Dourado, que havia de pouco se transformado em nova Califórnia. A Praça da República à noite, deslumbrava pela animação constante e ruidosa. As casas de diversões como o Café Chic, o Politeama, o Moulin-Rouge, o Café da Paz, o Apolo, o Circo Providência, o Chat Noir, o Chinez, O Café Madrid flamejavam cheias de constante multidão. Demis-Mondaine ricamente vestidas e carregando jóias de preço ostentavam suas belezas nas terrasses borbulhantes, o champagne espoucava nos bares, e os comerciantes donos de seringais opulentos, e corretores de negócio, exibiam jóias caras que cintilavam às 
luzes. Era assim, como um reflexo longínquo de Paris - luxo, mulheres e música! (MENEZES, 1954 citado por LEAL, 2002, p.22)

Junto à mão-de-obra que vinha para os trabalhos nos seringais juntou-se os trabalhadores das construções realizadas no tempo da "Belle-Époque"(como ficou conhecido o período do auge da exuberância regional que diz respeito aos benefícios materiais trazidos para a cidade) resultando no surgimento de

uma nova força de trabalho propriamente urbana, que vai se juntar a outros ofícios urbanos, como alfaiates, sapateiros, relojoeiros, marceneiros e outros. A composição desses grupos expressava a camada pobre da população. (SARGES, 2002, p.86)

A população pobre de Belém ficava sujeita às condições mais desfavoráveis, conforme encontra-se descrito no "Relatório da Comissão Brasileira junto a Missão Official Norte-Americana de Estudos do Valle do Amazonas", de 15 de Agosto de 1923, sistematizado por funcionários do Ministério da Agricultura, Indústria e Comércio (1924, p. 38):

\begin{abstract}
A edificação da cidade de Belém varia conforme os bairros. Sobresahem especialmente a parte commercial com um grande numero de edifícios vastos de estylo moderno e vivendas magníficas, villinos e palacetes confortáveis nas zonas de moradia. Alguns bairros pobres apresentam entre casas modestas de alvenaria, barracas de palha de ubussú.[...] As agglomerações humanas [...] só se podem desenvolver apoiadas numa série de medidas especiais contra todas as causas de destruição e ameaças de molestias provenientes da contaminação do ar, do sol e da água, tomadas pela communidade.[...] Todas as medidas hygienicas devem ser postas em pratica sem levar em conta os sacrificios que d'ahi advenham.[...] As communidades pagaram sempre caro a inobservância dos cuidados e escrúpulos que os trabalhos de hygiene merecem. Infelizmente Belém deixa muito a desejar neste sentido. Sua rede de esgottos é constituída apenas por um pequeno numero de collectores , insuficientes para as actuais exigencias da cidade. Esta recebe as águas pluviaes juntamente aos líquidos poluídos e às materiais putreciveis e lançam-nas na Bahia do Guajará ou nas Várzeas, que lhe são mais próximas, sem o imprescindível tratamento final na boca dos emisarios para tornal-os innocuos. Isto causa muitas das doenças enterias que enchem o obtuario desta capital.
\end{abstract}

Por outro lado, a sustentação econômica, baseada na extração da borracha, causou sérios problemas e eliminou qualquer ação política para o cultivo de outras culturas.

A mensagem proferida pelo Governador Lauro Sodré no dia $1^{\circ}$ de fevereiro de 1893, ao Congresso do Estado do Pará, retrata esta situação

[...] não pode contestação a verdade de que não tem entre nós dado passos para adiante a industria agrícola, que é aliás, a grande fonte perenne de riquezas sólidas e duradouras[...] Se não é um mal esse enorme desenvolvimento que tem tido a industria de borracha, e que tanto tem concorrido para a riqueza pública, é de certo grandemente para lamentar que tal crescimento tenha sido feito com prejuízo da agricultura em estado evidente de pobreza. (PARÁ, 1893, p.25)

Entre os produtos agrícolas da época, destacavam-se o cacau e a castanha, que mesmo em menor escala mantinham seu preço estável no mercado. Além desses, a baunilha, o cumaru, o óleo de copayba, a salsaparilha, a tapioca, o urucum, o café, o feijão, o fumo, o milho, produtos de natureza extrativa, que também poderiam fazer diferença na 
economia paraense não foram aproveitados em seu devido potencial econômico, e finalmente o algodão, o tabaco, o arroz, a cana-de-açúcar que poderiam melhorar sua produção se tivessem formas apropriadas de cultivo.

Além de ser apontada como responsável pelo atraso da agricultura, a extração da seringueira influenciava também na forma como as populações que viviam nas regiões produtivas tinham acesso às precárias alternativas que existiam para a educação. Pois as crianças (filhos dos seringueiros) eram afastadas da escola durante o verão. Estas constatações foram feitas nas visitas realizadas pelo conselheiro Joaquim Maria Nascentes de Azambuja em várias localidades do Pará e Amazonas. Em um dos trechos do relatório é afirmado:

Esta é a primeira causa da deserção de nossas escolas pelo habito que estão os seringueiros na estação própria da colheita, de se internarem com suas familias pelos mattos em busca daquelle producto, objeto principal de nossa exportação.

Coincide esta romaria com o segundo semestre do anno, e nessa época as escolas são pouco concorridas; os meninos que já alguma coisa sabião, desaprendem; se nada sabião, continuão analphabetos, porque não há mestres para dar-lhes a devida instrucção. É o que se observa nesta província e na do Pará.( AZAMBUJA, 1884 citado por RIZZINI, 2004, p.109)

O terceiro problema causado pela produção do látex dizia respeito à falta de mãode-obra, agravada pelo seguinte motivo: as lutas sangrentas no Estado do Pará, durante o movimento da Cabanagem, que levaram à morte milhares de pessoas.

Atento a esse problema desde antes da proclamação da República, o governo aprovou o Decreto $\mathrm{N}^{\circ} 1848$, de $28 / 10 / 1848$, favorecendo a criação de núcleos agrícolas, introdução de colonos estrangeiros nesses núcleos, concessão de favores a empresas ou indivíduos que assumissem essa iniciativa.

Os governadores Lauro Sodré ${ }^{3}$ (1891-1896/ 1917/1921) e Paes de Carvalho (18971901) no sentido de enfrentar esta realidade, organizaram um intenso programa de colonização para melhorar e ampliar os núcleos agrícolas e remunerar os colonos qualificados para que introduzissem métodos, práticas e hábitos de agricultura atualizada, e dessa forma, fossem reestruturados os núcleos rudimentares na faixa destinada à ferrovia Belém-Bragança.

Esses núcleos serviriam como pólos de recuperação da economia agrícola do estado e, ao mesmo tempo, como alternativa para que essa população "pobre" que se aglomerava pelas cidades morasse e produzisse.

Devido a essa situação, o ensino profissional, tal como no resto do Brasil, passou a ser muito discutido e considerado uma das ferramentas de mudança do perfil econômico do Pará, pois desde a primeira década do século XX, as produções asiáticas suplantaram o monopólio Amazônico na extração gomífera.

Importante ressaltar que a preocupação causada com os danos que a produção gomífera trazia à agricultura preocupava os dirigentes, mesmo antes dela entrarem decadência. Um dos fatos que comprovam esta preocupação encontra-se na fundação da Escola Rural D. Pedro II, com as leis No 372 de 18 de outubro e 3 de novembro de 1860.

A fundação desta escola estava relacionada à necessidade de reorganizar a vida econômica da província, uma vez que a economia pautada na produção da borracha enfraqueceu a agricultura local. A Escola Rural D.Pedro II tinha como objetivos:

[...] estimular a agricultura local, principalmente a pecuária e o plantio da cana de açúcar e de forma prática fazer experiência e observações sobre agricultura e propagar essas experiências e observações, 
principalmente,entre o povo (órfãos, desvalidos e jovens indigentes).(PARÁ, 1861, p.2)

No currículo deste estabelecimento de ensino, os conteúdos teóricos não eram privilegiados, pois se pretendia formar trabalhadores, operários, feitores e administradores para os estabelecimentos rurais.

[...] liga os educandos primeiro que tudo à prática dos trabalhos, ensinando-lhes a ler, gravar-lhes logo na memória os princípios da agricultura; e já nos campos de trabalho, já em conferências durante os serões mostrar-lhes a verdade e a aplicação desses princípios desenvolvendo-os convenientemente. (PARÁ, 1861, p.13)

Após essa escola ser fechada, foram inauguradas outras instituições de ensino rural, "como o Orfanato Antonio Lemos (ensino feminino), o Instituto Santo Antonio do Prata ([...] masculino e feminino) e o Instituto de Ourém ([...] masculino e feminino)" (NETO, 1996 citado por SOUZA 2002, p.28). Ainda foram criados o Liceu Benjamin Constant de Artes e Ofícios para as classes populares, e o Orfelinato, internato de órfãs desvalidas.

A mensagem que o governador Lauro Sodré proferiu no dia $1^{\circ}$ de Fevereiro de 1893 ao Congresso Legislativo do Pará mostra o momento histórico em que o estado estava vivenciando, ou seja, os primeiros anos do período Republicano:

Graças ao patriotismo e ao critério com que vão sendo guiadas as cousas publicas, dia-a-dia consolida-se a obra da revolução gloriosa a 15 de novembro, que fez de nós livres cidadãos de uma Republica, de humildes servos que eramos sob uma realeza exotica e bastarda. (PARÁ, 1893, p.5)

Nessa mesma mensagem, o governador Lauro Sodré expressava sua preocupação com a instrução pública, como uma das ferramentas para o progresso do Pará, pois neste período o ensino primário e profissional eram deficientíssimos:

[...] devem continuar a merecer-vos cuidadosa atenção os negocios do ensino publico, devemos prosseguir na tarefa encetada de levantar cada vez mais o nível moral do povo, pelo alargamento do ensino publico, levando-o a todas as camadas, semeando escolas por toda extensa area do nosso território, fazendo do mestre o instrumento da regeneração social [...] O problema estabelecido pela sociabilidade moderna, a encorporação do proletariado, nos paízes onde a revolução tem eliminado todos os odiosos privilégios de classes, há de resolver-se pela educação e pelo ensino. Sem que tenhamos em mira fazer do proletariado uma corporação de acadêmicos ou de sábio, e indispensável ministra-lhe o ensino geral das sciencias, que pondo ao alcance das suas intelligencias as leis naturales que regem todas as ordens de phenomenos, dará em rezultado não deixa-lo estranho ao que faz a honra,o bem estar e a força da sociedade no meio da qual é chamado a viver.[...] Armado de tal ensino terá o operário entre as mãos o instrumento util e fecundo de sua própria melhoria, de seu aperfeiçoamento.[...] Deveis cuidar da organisação do ensino profissional, acujo beneficio ainda uma vez reclamo [...] (PARÁ, 1893, p.17-18)

O conteúdo dessa mensagem confirma uma preocupação, mesmo que meramente teórica, com a educação das massas e a coloca como instrumento do progresso, ideal latente durante os primeiros anos da República.

Constata-se, ainda, a preocupação do Governador Lauro Sodré com a educação nos seguintes aspectos:

No governo Lauro Sodré a instrução pública era uma das metas específicas. Lauro criou o Liceu Benjamin Constant de Artes e Ofícios 
para as classes populares, e o Orfelinato, internato de órfãs desvalidas e fundou a Academia de Belas Artes com subvenção aos estudantes pobres, de maior êxito escolar, para aperfeiçoamento de estudos na Europa, atendeu, com zelo ao Liceu Paraense e a Escola Normal e difundiu escolas primárias no Estado [...] (BORGES, 1983, p.74)

Durante a República, foram realizadas várias ações para organizar o ensino agrícola no Pará. O Instituto Lauro Sodré ${ }^{4}$ teve seu novo prédio inaugurado em 10 de Setembro de 1889, no governo Paes de Carvalho, após passar por ampla reforma:

[...] o vasto e majestoso edifício tinha capacidade para internato de 300 meninos; 2 pavimentos, o superior com: dormitórios, banheiros, vestiário, enfermaria; o interior com salas de aula, de visitas e recepções, refeitórios, capelas [...]. Na vasta área restante, oficinas, residências de mestres e empregados, campos de recreio, esportes, estação experimental de agricultura, pois no seu esquema de governo preconizava tais estações como peculiares aos municípios do interior, e assim observaria seu sucessor, instalando a do município de Igarapé-Açu. Paes equipou o Instituto de Educandos e Artífices com instrumentos e material de trabalho de artes e ofícios inclusive 31 máquinas importadas, para as oficinas e estação experimental de agricultura, a este provendo de professores, catados entre os colonos estrangeiros. [...] (BORGES, 1983, p.150-151)

Pelo decreto $\mathrm{N}^{\mathrm{o}} 726$, de 12 de Julho de 1899, o curso industrial desse estabelecimento foi ampliado, e passou-se a ofertar-se também o curso agrícola. "Neste decreto os artigos $n^{\circ} 12, n^{\circ} 14$ e $n^{\circ} 20$ estabeleciam o currículo, e definiam os cursos ofertados. Passando a existir o curso primário geral e os profissionais agrícolas e os industriais"(SOUZA, 2002, p.30).

Em 1901, ainda no governo de Paes de Carvalho, foram concluídas as reformas neste instituto, transformando-o também em um estabelecimento de ensino agrícola, com posto zootécnico, leiteria, vacaria, estrumaria e campos agrícolas para plantação.

Em 1909, no governo de João Coelho, foi criado um campo experimental de agricultura nos terrenos do Lauro Sodré. Estas estações experimentais eram escolas práticas com o objetivo de preparar feitores agrícolas rapidamente. "Esses campos serviriam para demonstração de ensino prático de uma agricultura racional, superando os métodos rudimentares"(PARÁ, 1910 citado por SOUZA, 2002, p.31)

Em 23 de janeiro de 1918, foi fundado pelo governador Lauro Sodré o centro propagador das ciências, formado pela união de 12 pessoas que se propunham a estabelecer e superentender cursos em nível superior; dentre os quais encontrava-se o de Agronomia, voltado para o melhoramento do ensino agrícola no Pará.

Na mensagem proferida em 7 de setembro de 1919, ao Congresso Legislativo do Pará, o governador Lauro Sodré, já em seu segundo mandato, enaltece a educação profissional como ferramenta do progresso e faz referência ao Instituto de Educandos e Artífices, então já denominado Lauro Sodré:

O ensino techinico que o Estado dá é o que se recebe no Instituto Lauro Sodré, nome que lhe foi dado pelo meu sucessor quando deixei em 1897 o governo do Estado. Eu dei a este instituto de ensino profissional farto quinhão dos meus cuidados e attenções no governo logo nos primeiros annos do período em que me coube a direcção eu pleiteava em favor desse ensino mal tratado entre nós. Assim já em 1892: “A organisação do ensino technico, disse-o já alguém, não é uma simples questão vital para todos os povos modernos, empenhados nessa luta travada no terreno da produção e das ferramentas. Nos torneios de que hoje se entretece o 
drama da vida das nações policiadas, a victoria há de caber ao mais apparelhado, isto é, ao mais instruído" (PARÁ, 1919, p.120)

No governo de Paes de Carvalho destaca-se a criação das seguintes instituições como expressão da educação profissional no Pará:

O Instituto Orfanológico ${ }^{5}$ para recolher órfãos e desvalidos de 6 a 8 anos de idade e educá-los. Instalou-o na aprazível e salubre localidade de Outeiro, contígua à Vila de Pinheiro, atual Icoaraci [...] Criou o Instituto de Santo Antonio do Prata, município de Igarapé-Açu, na distante zona povoada de índios já catequisados e ansiosos de maior integração; fundou dois colégiospara meninos e meninas silvícolas e, ao mesmo tempo, uma colônia agrícola [...] Criou o Instituto de Ourém, município desse nome, à margem do rio guamá; idêntico ao do Prata, dois colégios, para meninas e meninos, respectivamente, colônia agrícola[...] (BORGES, 1983, p.152153)

As instituições de educação profissional fundadas no Pará tinham o objetivo de oferecer bases para o fortalecimento de novas atividades econômicas que dessem outras possibilidades de sustentabilidade ao Estado, pois na virada do século XIX para o XX, várias transformações culturais, econômicas e urbanísticas mudavam o perfil da cidade de Belém. Essa mudança estava diretamente relacionada ao crescimento econômico patrocinado pela produção e comercialização da borracha Amazônica.

Nesse contexto, havia uma elite que precisava impor um comportamento às camadas populares de controle e de disciplina, a fim de nivelar, dentro do possível, a capital paraense com as demais cidades européias.

Assim tínhamos uma elite com costumes europeus e um contingente populacional pobre, na maioria negra e cabocla, que precisava ser disciplinada.

As iniciativas voltadas para o ensino agrícola no Pará durante o final do século XIX e inicio do XX, confirmam duas características: a preocupação dos dirigentes em formar uma mão -de -obra para trabalhar na agricultura devido aos problemas causados a esta pela concentração da economia na produção da borracha; e o caráter assistencialista e regenerador que caracterizou a educação profissional no Pará nesse período

\section{3- A fundação do Patronato Agrícola Manoel Barata}

No Pará, com a decadência de uma economia pautada no extrativismo da borracha e na preocupação do poder público com alternativas de educação para outras classes que estavam presentes no cenário paraense, é fundado o Patronato Agrícola Manoel Barata.

O conteúdo do decreto que autorizou o governador Lauro Sodré a estabelecer acordo com o governo Federal para a fundação desta instituição demonstra as características da educação profissional para a época, implementada em grande parte do território brasileiro: destinada aos órfãos e desvalidos de fortuna e aos desfavorecidos da sorte, reforçando a dualidade existente na educação, uma destinada à elite condutora e outra para preparar as classes que iam servir como mão-de-obra.

No Pará, o Patronato Agrícola Manoel Barata foi considerado uma das ações institucionais para contribuir com a preparação daqueles que seriam os empregados das elites agropecuárias no estado.

A fundação do Patronato Agrícola Manoel Barata tem sua origem no acordo firmado entre o Governo do Estado do Pará e o Governo Federal, em 1920, quando foi outorgada a lei $\mathrm{N}^{\circ} 1957$, que transferiu para a união as terras da ilha de Caratateua, em Outeiro, distrito de Icoaraci, Belém (PA). 


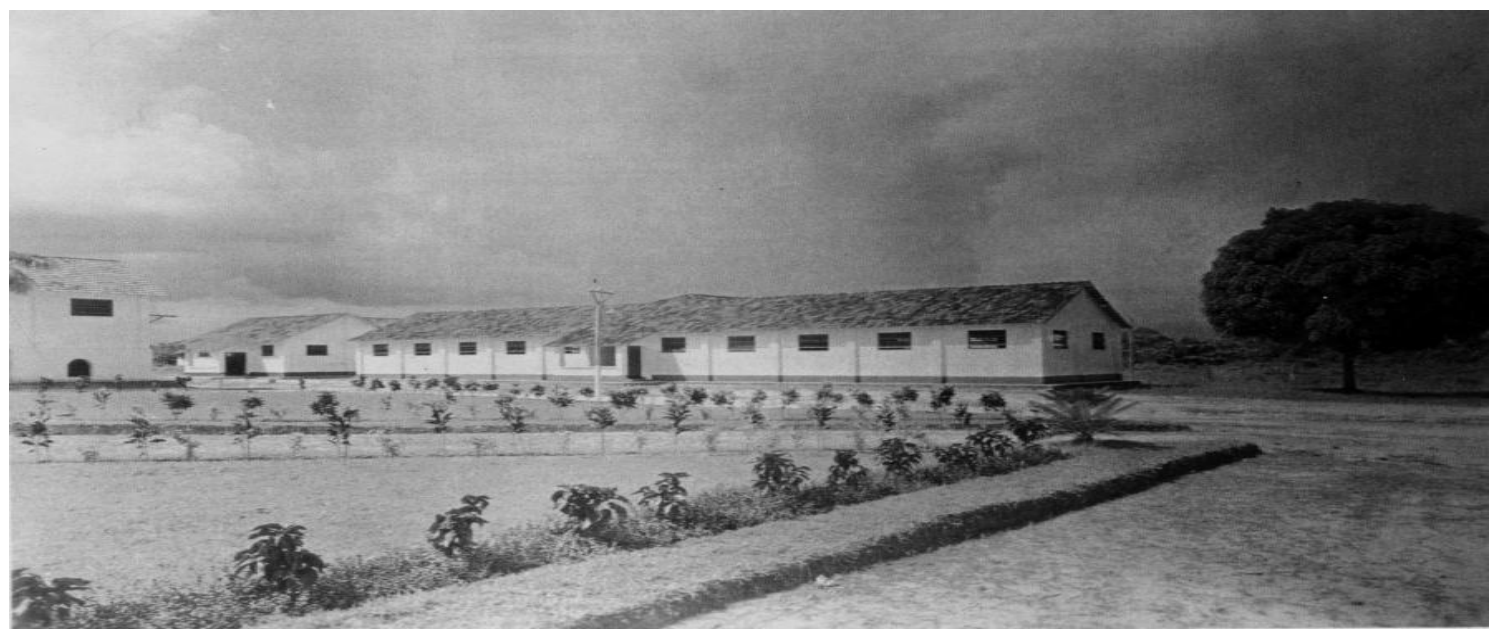

Figura 2: Algumas das dependências do Patronato Agrícola Manoel Barata - Outeiro-Belém-PA

Na Colleção Leis do Estado do Pará, anno de 1920 (p.101) encontra-se o Decreto Lei $\mathrm{N}^{\mathrm{o}} 1.957$, de 17 de Novembro de 1920, que transcrevemos abaixo o seu teor: DECRETO LEI No 1.957 DE 17 DE NOVEMBRO DE 1920 AUCTORIZA O GOVERNO DO ESTADO A ENTRAR EM ACCORDO COM O GOVERNO FEDERAL PARA A CRIAÇÃO DE UM PATRONATO AGRÍCOLA NESTE ESTADO.

O congresso Legislativo do Estado do Pará decretou e eu sancciono a seguinte lei:

ART. $1^{\circ}$-Fica o Governo do Estado auctorizado a entrar em accôrdo com o Governo Federal, a fim de ser por este installado no antigo Instituto do Outeiro um patronato Agrícola destinado a promover o desenvolvimento da agricultura, horticultura, pomicultura e jardinocultura, transformando menores orphãos ou abandonados em feitores do campo, pomicultores, horticultores, jardinocultores, abegões e profissionais práticos nos diversos offícios agrícolas.

Art $2^{\circ}-\mathrm{O}$ governo do Estado, no contracto que assignar no Ministério daAgricultura, Industria e Commercio, fará entrega das instalações, terras, machinas e dependências do estabelecimento, que reverterão ao Estado, desde que o governo federal não continue a manter o serviço.

Art. $3^{\circ}$-Revogam-se as disposições em contrário.

O Secretário Geral do Estado assim a faça executar.

Palácio do Governo do Estado do Pará, 17 de Novembro de 1920

(a.a.)Lauro Sodré

Barroso Rebello

Atendendo à solicitação do governador Lauro Sodré, o presidente Epitácio Pessoa criou a $1^{\circ}$ de Dezembro de 1921, o Patronato Agrícola Manoel Barata, através do Decreto Lei $\mathrm{N}^{\mathrm{o}}$ 15.149.O texto desse decreto encontra-se reproduzido na reportagem ${ }^{6}$ do jornal $\mathrm{O}$ Liberal de 18 de junho de 1972, na página 7: 
O Presidente da República dos Estados Unidos do Brasil, tendo em vista o disposto no artigo 64, verba $3^{\mathrm{a}}$ alínea "v" "v". "Título Maternal", da Lei $\mathrm{N}^{\circ} 4.242$, de 5 de janeiro de 1921 ,

DECRETA:

Artigo I- Fica criado um Patronato Agrícola no Município de OuteiroEstado do Pará- sob a denominação de "Manoel Barata", que será regido pelo regulamento aprovado pelo Decreto $\mathrm{N}^{\circ} 13.076$ de 5 de Julho de 1919.

Artigo II- Revogam-se as disposições em contrário.

Rio de Janeiro, $1^{\circ}$ de dezembro de $1921,100^{\circ}$ aniversário da Independência e $33^{\circ}$ da República.

aa)EPITÁCIO PESSOA/ Simões Lopes

A criação desta instituição representou um marco do ensino rural/ profissional na Amazônia, pois foi a primeira ação federal direcionada para o ensino Agrícola no Estado do Pará, com objetivo de desenvolver a Agricultura, Horticultura, Jardinocultura, para as crianças de classe popular, direcionando-as para o trabalho rural. Um dos resultados esperados com a fundação desses patronatos era estabelecer o equilíbrio entre a população das cidades e a fixada nos campos, como forma de restabelecer o controle social ao concorrer para imobilidade da força de trabalho, estimulando a fixação da população rural.

Esperava-se também que a economia nacional fosse beneficiada, pois o aumento da produção seria obtido à medida que os patronatos agrícolas interviessem sobre diversas situações, tais como:

[...] minorar os problemas decorrentes da falta de preparação daqueles que trabalhavam e diretamente lidavam com agropecuária. Para consecução dessa finalidade, a implantação do ensinoagrícola era um dos objetivos, sendo as unidades institucionais então apontadas como integrantes do que viria a configurar o suporte organizacional para implementação daquela vertente do ensino profissional, da qual era esperada a capacidade de contribuir para tornar mais frutuosa a produçãoagropecuária. Paralelamente, concorrerá para estabelecer o equilíbrio entre a população das cidadese a população dos campos, ao governo caberia, enquanto um dever seu, contribuir para aumentar apopulação rural e formar o verdadeiro agricultor brasileiro. Os patronatos agrícolas eram inscritos entre os investimentos voltados para intervir ante a mão- de - obra disponível e com origem no país. Esta era alçada, progressivamente, a uma outra posição nos diagnósticos, propostas e projetos: como fator de riqueza o elemento nacional. (OLIVEIRA, 2003, p.26-27, grifos no original)

Para estas instituições deveriam ser encaminhados :

[...]a infância que estava pelas ruas, os órfãos, os que eram tomados pelas forças de segurança e aqueles que seus responsáveis declaravam sem recursos para mantê-los ou por serem de difícil controle. Assim o perfil institucional dos patronatos agrícolas era voltado para o disciplinamento e o correcional.(OLIVEIRA, 2003, p.32) 


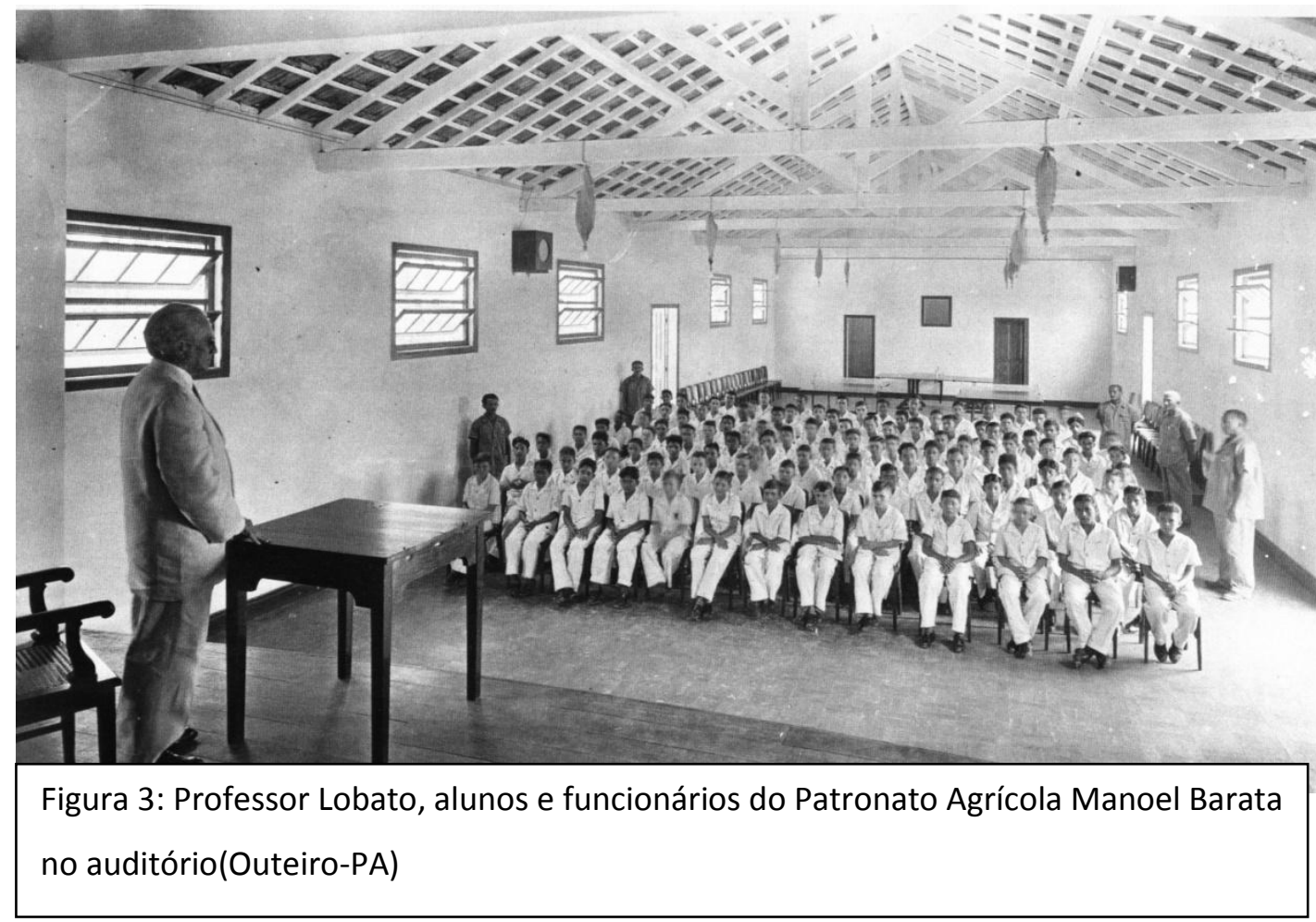

Eram instituições de assistência social "destinadas a abrigar e educar menores, preocupadas em readaptá-los à vida social”. (NASCIMENTO, 2003, p.136)

Detalhes da foto acima ilustram o caráter disciplinador da formação ministrada no Patronato Agrícola Manoel Barata. Observa-se que os "meninos" encontram-se sentados na mesma posição e vigiados por cinco "inspetores". Além deste detalhe, observa-se o uniforme que estes portavam, todos impecavelmente iguais.

O primeiro diretor do Patronato Agrícola Manoel Barata foi o Sr. Juvenal PinheiroMarques Canário. A organização das instalações, do corpo técnico e docente levou um período de dois anos, o que fez com que essa escola fosse inaugurada oficialmente em 7 de setembro de 1922. Inicialmente, as vagas foram destinadas somente para o sexo masculino, confirmando uma das características do ensino profissionalizante nos primeiros anos da república, onde o sexo feminino não tinha acesso a essas escolas.

O patronato foi idealizado para ser auto-sustentável, por isso as criações e plantações tinham objetivo pedagógico e também de propiciar ao refeitório da escola a alimentação necessária aos alunos residentes, caracterizando esta como uma fazendaescola, forma de organização que é considerada até hoje. As atividades eram mais práticas que teóricas, com ênfase na capacitação dos pequenos filhos de agricultores para que fossem futuros empregados das fazendas de porte médio e grande daquela época.

O público atendido no Patronato Agrícola Manoel Barata era composto de filhos de agricultores, com diversidade de faixa etária média entre 11e 12 anos, por se tratar ainda de uma escola primária. Para atender a demanda social, a faixa etária da clientela atendida foi aumentada e novas séries foram inseridas.

Com base nas cartas encontradas no Setor de Registros Escolares, nas pastas dos alunos, constatamos que a maioria deles era proveniente de famílias de pequenos agricultores, existindo alguns raros de classe social mais abastada, os quais foram matriculados a pedido da família, para que fossem disciplinados. Esses alunos eram provenientes de vários municípios do estado do Pará. A carta transcrita abaixo comprova o 
perfil assistencialista do Patronato Agrícola Manoel Barata que permaneceu por muitos anos como uma das características da instituição.

$\mathrm{ILm}^{\circ} \mathrm{Sr}^{\circ}$ Diretor da Escola Agrícola Manoel Barata neste estado.

Creusa dos Santos Carneiro, requer a inscrição aos exames vestibulares do curso de Mestria Agrícola deste estabelecimento de ensino agrícola do menor Francisco dos Santos Carneiro, com a idade de 14 anos natural de Alenquer, estado do Pará, nascido a 4 de setembro de 1944, residente em Belém , a travessa Soares Carneiro, 421, filho de Olavo Carneiro Monteiro (falecido) e Idalzina Alves Santos.(SETOR DE REGISTROS ESCOLARES DA EAFC-PA )

O conteúdo da carta ressalta o fato de o menor ser órfão de pai.

A educação baseada na moral e na disciplina do Patronato Agrícola Manoel Barata servia aos interesses de seus fundadores: as elites oligárquicas e industriais e as políticas para alcançar as metas econômicas do setor agrário.

Durante os primeiros anos da República, a educação profissional era utilizada para reafirmar a divisão de classes, perpetuar os papéis sociais e garantir a ordem necessária ao sistema capitalista que se expandia no Brasil.

O patronato agrícola, fundado no Pará, também consistia numa ferramenta do Governo Federal para difundir a nova ordem econômica, configurando a educação ministrada nessa instituição como um instrumento ideológico, que buscava difundir concepções e valores.

O currículo dessa instituição tinha como objetivo cumprir as seguintes funções: preparar o elemento produtor, oferecer instrução primária e formação moral e cívica aqueles que a ele acorressem. O currículo era alicerçado em conteúdos eminentemente práticos, mas sem desprezar os conteúdos teóricos. A rotina era com o objetivo de preparar esses menores para o exercício profissional, nas áreas de "agricultura, horticultura, pomicultura e jardinocultura", conforme encontra-se especificado no Art. $1^{\circ}$ do Decreto Lei $\mathrm{N}^{\mathrm{o}} 1.957$, de 17 de Novembro de 1920.

Nessa perspectiva educacional, a rotina do patronato agrícola seguia os moldes militares, onde os alunos acordavam, tomavam café, faziam educação física, estudavam, almoçavam e à tarde tinham atividades práticas no campo. Essas atividades visavam formar no aluno aspectos mais práticos, pois a aprendizagem era baseada no fazer do aluno no campo para transformar menores "orphãos ou abandonados em feitores do campo, pomicultores, horticultores, jardinocultores, abegões e profissionais práticos nos diversos oficios do campo". (Decreto-Lei № 1.957 de 17 de novembro de 1920, Art. $1^{\circ}$ ).

A ênfase em conteúdos práticos mostrava a preocupação dos patronatos com a preparação de trabalhadores para a atividade agropecuária e não com a formação de técnicos, pois pretendia-se que, por meio do ensino agrícola, o contingente que estava propenso a migrar do campo para cidade se fixasse no campo, "pois uma parte dos problemas urbanos daquela época eram pensados tomando por base o campo, concebido como uma de suas origens". (NASCIMENTO, 2003, p.138)

A instrução primária era ministrada a esses alunos nas séries iniciais com ênfase no ensino da leitura e escrita, conforme consta no regulamento da criação dos patronatos agrícolas no Brasil, Decreto $N^{\circ} 13076$, de 25 de julho de 1919,

[...] curso primário e o ensino profissional, compreendendo este último estudo de solo, instrumentos agrários, escolha de sementes, preparação e aproveitamento de matérias fertilizantes, jardinocultura, insetos úteis e prejudiciais à agricultura, pecuária, higiene, laticínios, apicultura, sericicultura, beneficiamento e embalagens dos produtos da lavoura, contabilidade agrícola etc. (NAGLE, 1976, p 183-184, grifos nossos) 
No entanto, cabe ressaltar qual era o verdadeiro sentido e objetivo da instrução elementar (ensino primário) ministrada nesses estabelecimentos, ou seja, sua função maior era formar na população ignorante uma conduta regeneradora e disciplinadora para o trabalho, tornando-os capacitados para os padrões de eficiência exigidos pela estrutura de poder dominante. A este respeito Mendonça (1993, citada por FEITOSA, 2006, p. 78) explica que esta educação estava muito distante dos ideais "que pregavam a promoção do ensino primário junto à massa analfabeta como elemento promotor da democracia, culminando no otimismo pedagógico da década de 1920".

\section{4- Conclusão:}

A fundação do Patronato Agrícola Manoel Barata, no período Republicano, foi parte de uma política nacional com o objetivo de "higienizar", ou seja, retirar do convívio social a "infância e juventude pobre", que com seus hábitos e atitudes incomodava e comprometia o projeto da elite oligárquica do período.

Para conseguir alcançar esse objetivo, os meninos eram retirados do convívio social e, através do "trabalho no campo" ensinavam-se a esses menores os meios práticos de lavrar a terra, plantar, colher e cuidar dos animais. O trabalho no campo era considerado o elemento regenerador, capaz de corrigir as vicissitudes destes menores desvalidos. No Patronato Agrícola Manoel Barata, esses meninos aprenderiam a conviver na sociedade para serem os empregados que esta elite ainda necessitava.

A formação moral e cívica era ministrada por meio das normas disciplinares e do poder regenerador do trabalho que estes menores executavam no campo.

O significado do nome da instituição, ou seja, o termo "patronato" retrata o objetivo disciplinador da educação profissional no período Republicano. De acordo com Tersariol (1996 citado por SOUZA, 2002, p.51) Patronato significa: "abrigo; patrocinio, autoridade de patrão; padroado; estabelecimento onde se abrigam menores e lhes dá instrução".

Esse termo refletia a conjuntura na qual estava organizada a educação profissional daquela época, nos primeiros anos da República, onde o trabalhador era capacitado para o papel de empregado, executor de ofícios manuais para uma economia que começava a se urbanizar e a substituir o trabalho escravo no campo pelo trabalho assalariado. Por isso era dada tanta importância à disciplina rígida no patronato, pois esse era o instrumento defendido pelas elites como forma de educação para o trabalho e obediência ao patrão.

Dessa forma, nesse período aquela instituição não pôde ser considerada de ensino técnico, mas um estabelecimento onde o objetivo principal era o "caráter corretivo", pois esses meninos eram considerados como os de inteligência mais rude e seria o público apropriado para o trabalho necessário à lavoura.

\section{Referências}

BORGES, Ricardo.O Pará Republicano.1824-1929 .Ensaio Histórico. Belém: Conselho Estadual de Cultura, 1983.

BRASIL, Ministério da Agricultura Indústria e Commercio. Relatório da Comissão Brasileira junto à missão official Norte Americana de Estudos do Valle do Amazonas. Rio de Janeiro: Officinas Typographicas do Serviço de Informações do Ministério da Agricultura, 1924. 
FEITOSA, André Dias Fidelis. A Trajetória do Ensino Agrícola no Brasil no Contexto do Capitalismo. 2006. 178p. Dissertação de Mestrado apresentada ao Programa de PósGraduação da Universidade Federal Fluminense, Rio de Janeiro: UFRJ, 2006.

LEAL, Luiz Augusto Pinheiro. Deixai a Política da Capoeiragem Gritar: Capoeiras e Discursosde Vadiagem no Pará Republicano (1888-1906).2002. Dissertação de mestrado apresentada ao Departamento de História da Faculdade de Filosofia e Ciências Humanas da Universidade Federal da Bahia, Bahia: UFBA, 2002.

MANFREDI, Silvia Maria. Educação Profissional no Brasil. São Paulo: Cortez, 2002.

MONTEIRO, Benedicto. História do Pará. Pará: Editora Amazônia, 2005.

MANOEL BARATA Disse Adeus. O Liberal, Belém, 18 jun.1972. Caderno de Domingo, p.7.

NAGLE, Jorge. Educação e Sociedade na Primeira República. São Paulo: EPU, 1976.

NASCIMENTO, Jorge Carvalho do. Educação e Trabalho:o processo de formação na Escola Agrotécnica Federal de São Cristóvão. Revista do Mestrado em Educação, Sergipe: UFSE, v.7, jul./dez., 2003, p.135-158.

OLIVEIRA, Formar Cidadãos Úteis: Os Patronatos Agrícolas e a Infância Pobre na Primeira República. Bragança Paulista: Editora Universitária São Francisco, 2003.

PARÁ, Mensagem apresentada ao Congresso do Estado do Pará. Pará: Diário Ofissial do Estado, Typ. do Diário Ofissial, 1893.

Mensagem apresentada ao Congresso Legislativo do Estado do Pará, em sessão solene de abertura da $2^{a}$ reunião de sua $40^{\circ}$ legislatura a 7 de setembro de 1919 . Belém, PA: Imprensa Ofissial do Estado, 1919.

RIZZINI, Irma. O Cidadão Polido e o Selvagem Bruto: a educação dos meninos desvalidos na Amazônia Imperial.2004.444 f. Tese de Doutorado.(Programa de pós Graduação em História Social). Instituto de Filosofia e Ciências Sociais da Universidade Federal do Rio de Janeiro, Rio de Janeiro, 2004.

SARGES, Maria de Nazaré. Riquezas produzindo a belle-époque(1870-1912). Belém: Paka-Tatu, 2002.

SILVA, Manoel Luiz. Reminiscências de Patronato Agrícola a Colégio Agrícola: 80 anos de História.Bananeiras,Paraíba: Gráfica Universitária, 2004.

SOUZA, Nieda Damasceno de. Lembranças do Patronato Manoel Barata:Memória da EAFCde Castanhal-PA(1921/1972). 76p. Trabalho de Conclusão de Curso de Licenciatura plena em Pedagogia, Campus Universitário de Castanhal, UFPA, Castanhal, 2002.

\section{Notas}

\footnotetext{
${ }^{1}$ Esta comissão foi chefiada pelo engenheiro João Luderitz, contratado pelo Ministério da Agricultura, Indústria e Comércio, em 1920. (NAGLE, 1976, p.163)

${ }^{2}$ De acordo com Salles (1994 citado por LEAL, 2002, p. 24) uma boa parte dos imigrantes nordestinos veio para Amazônia "espontaneamente". Desde a seca de 1877 que famílias inteiras se deslocavam para a região em busca de melhores condições de vida e de trabalho. Em particular para a lavoura e a extração do látex nos seringais.
} 
${ }^{3}$ O governador Lauro Sodré teve dois mandatos.

${ }^{4}$ Segundo Borges (1983, p.150) o Instituto Lauro Sodré foi idealizado pelo presidente da Província, João Alfredo Correia de Oliveira, em 1870, mas foi construído e começou a funcionar em 1872 com o nome de Instituto de Educandos e Artífices. Após 19 anos de funcionamento, no governo de Justo Chermont foi elaboradoo projeto da nova sede. A construção desse novo prédio do Colégio Lauro Sodré começou no primeiro mandato do governador Lauro Sodré e terminou no governo de Paes de Carvalho.

${ }^{5}$ Pela Lei $\mathrm{n}^{\circ} 1.957$ de 17 de Novembro de 1920, foi fundado o Patronato Agrícola Manoel Barata no lugar onde funcionava o Instituto Orfanológico do Estado. No artigo publicado no Jornal O Liberal de 18 de Junho de 1972, caderno de Domingo, p.7 faz referência ao decreto de criação do Patronato Agrícola Manoel Barata, e explica que antes do patronato, neste local funcionava este instituto.

6 "MANOEL BARATA DISSE ADEUS", foi a reportagem escrita sobre a transferência do Patronato AgrícolaManoel Barata, da Ilha de Caratateua (Outeiro ) para a cidade de Castanhal. A transferência foi autorizada pelo Decreto No 7.068 de 8 de junho de 1972 .

Recebido em: $\quad$ 20/10/2011

Aprovado em: $\quad 30 / 10 / 2011$ 